\title{
SAFE MOTHERHOOD PRACTICES \\ IN PANCH POKHARI THANGPAL RURAL MUNICIPALITY, NEPAL
}

Pasa Rajan Binayek, Giri Sunita, Dani Nabina ${ }^{8 *}$

\begin{abstract}
This paper highlights on safe motherhood practices in a rural municipality in Nepal. Primary data are collected through the survey questionnaire from 196 respondents who are married women of reproductive age group. The findings show that knowledge and practices on safe motherhood practices are moderately satisfied. The majority of the delivery cases are being handled in the health posts at a prolonged labor stage with the support of their husbands. The cord-cutting practice is also becoming scientific with the use of using sterilized scissors. Mothers are happily practicing the breastfeeding culture at least for two to three years after delivery. However, the rural mothers are facing problems such as vomiting, bleeding, anemia swelling of the leg, back aching, and head aching during pregnant periods, possibly due to the traditional treatment practices and the local food habits. Majorities of the respondents have good knowledge of contraceptives devices, but they prefer to report on health posts only for a postnatal checkup. All in all, safe motherhood practices in the rural community are found moderately adequate and needed to be improved by offering antenatal, natal, and postnatal services at no cost.
\end{abstract}

\section{Keywords:}

Maternal mortality, Reproductive health, Risk factors. Safe motherhood,

\section{Introduction}

Safe motherhood is universally defined as one of the central components of reproductive health. It practices begin in childhood. A female child, who is malnourished from birth or subjected to adulthood with anemia physical anomalies and possible psychosexual trauma will have to bear a high risk of unsafe motherhood. The safe motherhood relies upon increasing the circumstances within which a woman is enabled to opt whether she becomes pregnant or not and whether she is s ensured that she receives care for prevention and treatment of pregnancy complications or not. The cause of the low life expectancy of females is attributed to the high mortality of girl children and women during the childbearing years (Ashford, 2001). Hence, for the female of reproductive age,

$8{ }^{*}$ Dr. Pasa is Assistant Professor at Tribhuvan University Central Department of Rural Development

Email for correspondence: rajan.pasa@cdrd.tu.edu.np 
the biological functions of pregnancy and childbirth demand additional health needs (UN, 2015). Every year 35-40 million women suffer acute pregnancy-related complications problems and 10-20 million are at risk to lose their lives due to unsafe motherhood practices (Patel, 2000). Similarly, 5.6 million children under age five died in 2015 (15 000 every day) and the infant mortality rate of the world was 49.4 (OECD, 2016). The fertility rate was 6.0, 5.6, and 2.083 in 1952/54, 1991, and 2018 respectively (Luitel, 2004; WB, 2019). The fact indicates that among the demographic changes during the last three decades, the decline in the total fertility rate (TFR) has been the most striking in Nepal. It could be argued that the determinants of fertility and mortality in Nepal are poverty, early marriage, joint family system, low education level, religious/cultural values, inadequate contraceptives, infant and child mortality, and low status of women in society (Luitel, 2004).

Maternal Mortality Rate (per 100,000 live births) in Nepal is 239 and is targeted to reduce to 125 by 2020/21 (MoHA, 2018). Maternal mortality is a leading cause of the death of women of the reproductive age in developing countries. Out of the estimated total of 536000 maternal deaths worldwide, more than half a million women die every year during pregnancy and delivery stage. The developing countries account for 99\% (533000) of the maternal mortality deaths (UNICEF, 2001). Sub-Saharan Africa and South Asia account for $86 \%$ of global maternal deaths. The maternal mortality rate is still high in Nepal. According to Nepal Demographic Health Survey, the country experiences 281 maternal deaths per 100,000 live births (Subedi, 2002). Frequent pregnancies and inadequate nourishment to the women during pregnancy put women at high-risk during the delivery stage (Ashford, 2001). Likewise, poor maternal care during pregnancy and delivery are responsible for high maternal mortality. Data revealed that more than $80 \%$ of births were delivered at home and $44 \%$ of mothers received antenatal care from skilled birth attendants(SBAs) during late 2010(Bhandari,2012).

The family planning and maternal-child health program were initiated from the 1950s worldwide. In 1987, WHO conducted an international conference in Nairobi, Kenya, about safe motherhood. In the conference, all nations agreed to implement a safe motherhood program at the national level, which was implemented in Nepal after 1993 (Khand, 2001). The safe motherhood program covered safe pregnant, safe delivery, post-natal care, and the birth of a healthy baby. The focus of the safe motherhood program was to reduce the mortality rate of women during pregnancy, natal, and postnatal periods. Maternity care implies the provision of essential care for pregnant women to ensure safe delivery including postnatal care and treatment of complications of the mother and the newborn baby. Maternity care starts from the time of pregnancy diagnosis and is continued throughout the delivery and postnatal period (Adhikari, 2010). The safe motherhood 
initiative was developed globally as a result of the unacceptably high maternal mortality in many developing countries in the world where the average life expectancy of women was lesser than that of the man. In developing regions, maternal care was increased from $65 \%$ in 1990 to $83 \%$ in 2012. Only half of women in developing regions receive the sufficient health care facility. Due to which more than six million children still die before their fifth birthday each year (UN, 2015). However, in Eastern Asia, Northern Africa, and Southern Asia, maternal mortality has declined by around two-thirds. These terrifying data in the deaths of mothers and young infants indicates that there needs improvement in maternal and newborn health and care services, including fertility regulation services, and keeping safe motherhood practices at a high priority on national health and development agendas.

In this regard, the globally recommended areas for promotion of maternal and newborn health are developing capacities of women, families, and communities to stay healthy, make healthy decisions, respond to obstetric and neonatal emergencies; increasing awareness of women, families, and communities of their sexual and reproductive rights and the needs and potential problems related to maternal and newborn health; strengthening linkages for social support between women, men, families, and communities and with the health care delivery system; improving quality of care, health services, and health provider interactions with women, men, families and communities (Portela \& Santarelli, 2003, pp 60-62. Locally, Bhandari (2012, p.68), has also suggested some ways to promote maternal health, which are to improve access to increase utilization of health services; take maternal service affordable at all level for creating demand; produce trained skilled human resources and expansion/decentralization of health facilities intervention against sociocultural practice and involvement of male in maternal health care; improve women status in the household and society and establish communication network and develop awareness on maternal health care. At the same time, the Government of Nepal has restructured the Ministry of Health and Population and Department of Health by establishing Provincial Health Directorate and Provincial Health Offices. Similarly, health-related policies such as the Public Health Service Act, Safer Motherhood \& Reproductive Health Act, and the Social Health Insurance Act have been promulgated in the country (MoHA, 2018). In this background, this study has tried to analyze safe motherhood practices in the Panch Pokhari Thangpal Rural Municipality in Sindhupalchwok District, which is around fifty kilometers far from Kathmandu Valley.

\section{Objectives}

- To examine the socio-demographic characteristics of the marid wommne of the reproductive age of Panchpokhari Thangpal Rural Municipality. 
- To analyze the knowledge and practice of unsafe motherhood in the study area.

- To assess the risk factors for unsafe maternal practice in the study area.

\section{Methodology: Materials and Methods}

Philosophically this study is based on an objective ontological stance with deductive logic generation process or epistemology (Moore \& Bruder, 2007). In doing so, the post-positivist paradigm (explaining absolute truth) and the trend survey method, which follows a quasi-experimental research design have been applied (Creswell, 2014; Gupta \& Gupta, 2015). The survey was purposively conducted in Panch Pokhari Thangpal Rural Municipality of Sindhupalchwok District. This study had identified $\mathbf{4 3 0}$ married women of reproductive age group as the population of the study (PPTRM, 2019). Out of the population, 196 sample respondents were selected randomly, which was generated with a $95 \%$ confidence level and $5 \%$ marginal error by using sample size determination formula (Krejcie \& Morgan, 1970). The collected data has been analyzed by organizing, describing, and summarizing methods (Yin, 2014).

\section{Results: Social Demography of the Respondents}

Generally, educated persons prefer late marriage age as they are aware of the use of family planning methods and the consequences of the big family size. In this survey, out of 196 respondents, $44.38 \%$ of the respondents were literate and $8.67 \%$ were illiterate. Similarly, $20.40 \%$ had completed primary level education, $13.24 \%$ had completed the lower secondary level, $8.67 \%$ had completed secondary level, and only $4.59 \%$ had completed the intermediate level. During the key informant interviews, participants expressed that the educational status of the community was not satisfactory in their settlements, due to which $39.78 \%$ of the respondents still had agriculture as their primary occupation. Only $8.16 \%$ wereengaged in the service sector and $6.12 \%$ were engaged in business. $39.28 \%$ of the respondents did arrange marriage or traditional marriage, $58.67 \%$ chose their life partners themselves, and $2.07 \%$ of females did second marriage after their first husband died. The trend of doing love marriage was rampant in the study area. This could be the result of early biological maturity in girls and boys, and due to the exogenous factors, such as influenced modernity. The love marriage had fostered the early marriage, high fertility rate, and risks on the reproductive health of women.79.08\% of the respondents were living with their husbands and the husbands of $17 \%$ of the respondents were out of the village. Regarding the marriage age of the respondents, 33.16\% of the respondents were married at the age of 16 to 18 years and $20.40 \%$ at 18 to 20 years. Similarly, $26.53 \%$ of the respondents were married at the age of 20 years above. Interestingly $19.89 \%$ were married at less than 14 years. Therefore, the population of 16-18 years of marriage group of the respondents was higher, and that of less 
than 14 years of marriage age was lower. The data indicates that there is a trend of early marriage in the rural settlements in Nepal, which has promoted the early pregnancy and delivery practices. This is further supported by Singh and Samara, who have pointed out that the average marriage age of women in the developing countries begins from 16 years of age (Singh \& Samarat 1996).

\section{Knowledge and Practice of Unsafe Motherhood Practices}

Knowledge is simply the exploration of the relationship of the study of variables in contemporary research culture (Badal, 2019). The national programs in women's health regarding the antenatal, natal, and postnatal stages have encouraged women to deliver children at health centers under the care of skilled attendants. The health centers should be feasible with the facilities and trained health workers to handle the complications during the delivery stages. At the national level, the figure shows that only $9.0 \%$ of the children are born at health centers, and still $89 \%$ of them are born at home $(\mathrm{MoH}, 2001)$. In the case of safe delivery practices, $8.16 \%$ of the respondents had delivered their children at home, under the care of TBA (Traditional Birth Attendant) and $11.73 \%$ had delivered a child at their own home without TBA. Similarly, $72.44 \%$ of the respondents had delivered children in health posts and only $7.65 \%$ had delivered children at a private clinic. Therefore, the result has shown that the child delivery rate at public health post is still higher than at the private clinics in Nepal.

Similarly, no or very less transportation service to reach the health centers is one of the major causes for raising the maternal mortality in Nepal. $33.16 \%$ of the respondents were transported to the health centers during the prolonged labor period. Likewise, $25.51 \%$ of the respondents were transported at their first stage of labor pain. The $8.67 \%$ of the respondents had cut the umbilical cord of their babies with sterile blades, $2.04 \%$ cut with un-sterile blades, $5.80 \%$ cut with knives, and only $84.18 \%$ cut with sharp scissors. complications found that the cutting of umbilical cord was being done unsafely. A WHO report also claims that every single minute, a woman dies from complication of pregnancy during childbirth and unsafe abortion (WHO 2000). The $18 \%$ of the respondents had also faced delivery complications. Among the different complications, $81 \%$ of the respondents had suffered from vaginal bleeding. and $2.04 \%$ had suffered from fever. $3.06 \%$ of the respondent had grieved from the excessive bleeding. Only $4.08 \%$ of the respondents had suffered from cephalic pelvic dispersion and1.53\%uffered from mal presentation. In case of postnatal Care Servces, $85 \%$ of the respondents had fed the colostrum to their babies and $14.28 \%$ of them had not fed yet. Regarding personal hygiene, only $31 \%$ of the respondents were taking the daily bath and changing clean clothes. The $34 \%$ of them did the cleanliness of. breasts' nipples. It was good to learn that percent of respondents had immunized their children. 
In case of taking rest after delivery, a mother needs complete bed rest for at least 3 weeks to maintain her physical fitness. But the empirical data showed that $85 \%$ of the respondents were involved in household chores during the rest periods. Similarly, in the case of postnatal health checkups, $88.26 \%$ of the respondents reported that they attended postnatal checkups. In the case of using contraceptives, $67 \%$ of the respondents used contraceptives devices during the postnatal period. Out of those, who used contraceptives, the husband of $70 \%$ of respondents had decided to use such devices. About $8 \%$ of the respondents revealed that they were suggested by the health workers and their friends for the use of contraceptives. Regarding the micronutrient's deficiency, $73.87 \%$ of the respondents had the food containing micro-nutrients because of their good economic status and aware family members. Likewise, in the case of breastfeeding, $70.40 \%$ of the respondents had continued breastfeeding to their child up to two years, $13.77 \%$ up to three, $12.24 \%$ up to one, and $3.57 \%$ up to more than three.

\section{Risk Factors for the Unsafe Safe Motherhood Practice}

Confirmation of pregnancy makes a mother conscious about her health and fetus. It is good to confirm being pregnant as soon as possible. However, the confirmation checkup must be done by skilled health personnel. Otherwise, there might be more chances of danger for the mother and fetus. The data revealed that most of the mother had self-confirmed their pregnancy as their regular menstruation cycle was stopped. About $19.38 \%$ of the respondents had confirmed through the feeling of getting morning sickness, $6.12 \%$ had confirmed by realizing the increase in the size of their abdomen, and $46.93 \%$ of the respondents confirmed by the urine test. The pregnancy checkup is quite essential for the health of the mother and fetus. The practice of safe motherhood can be assessed according to the type of health service providers, the number of visits made by a pregnant woman in the health center, and the guidance provided to the women during the checkups. The data showed that $86.22 \%$ of the respondents had their health checkups during pregnancy due to the accessibility of health centers with child delivery services. However, $13.77 \%$ of the respondents hadn't done health check-ups during pregnancy. It could be due to the lack of knowledge about the utilization of antenatal care service and the awareness of women's health.

Regarding the frequency of visiting the health checkup centers, about $54.59 \%$ of the respondents had visited for four or more times during their entire pregnancy period. About $11 \%$ had done two times visit and $8 \%$ had a single visit for the health checkup during their entire pregnancy stage. Similarly, $91.89 \%$ of the respondents were vaccinated by the T.T vaccine in full dose. About $17 \%$ of the respondents had not taken a full dose of the vaccine and only $8.16 \%$ had not injected any kind of vaccine. Likewise, during the pregnant period, $41 \%$ of respondents had got help from their 
husbands, 34.69\% from their mother in law, and $11.33 \%$ from their mother, 9.1\% from their friend, and only $3 \%$ of them from the health workers. Regarding the consumption of unwanted things during the pregnancy period, $35 \%$ of pregnant women had smoked, $33 \%$ had drunk alcohol, $15 \%$ had eaten mud and ash, $10 \%$ had taken chocolates, and $7 \%$ had taken tobacco. With this information, it can be concluded that most pregnant women have been practicing unhealthy food consumption habits, which is harmful to their health. Because of these unhealthy lifestyles, $50 \%$ of the respondents had felt the problems of vomiting time to time during the pregnancy period, $2.55 \%$ witnessed bleeding from the vagina, $5.61 \%$ realized the leg swellings, $7.14 \%$ felt the problems of backache, and $7.14 \%$ sensed the headache problem.

\section{Conclusion}

Based on the empirical findings this paper has come up with the conclusions that knowledge and practices on safe motherhood habits in the settlement in Panch Pokhari Thangpal Rural Municipality are moderately satisfied. Most of the delivery cases are being handled in health posts by taking help from husbands during the prolonged labor stage. The cord-cutting practice also seems scientific as the use of the sterilized scissors is done by many of the respondents. The immunization trend of mothers and children seems significantly increasing. However, the breastfeeding period is reducing as the majority of most of the lactating mothers are doing the feeding for their newborn baby only till two years of age. Most of the women have suffered from vaginal bleeding complications. The respondents having good knowledge of the use of contractive devices have preferred to attend the postnatal checkups. Vomiting, bleeding, anemia, swelling of legs, backache, and headache problems are the risk factors, being faced by the women in the rural settlement in the municipality. These health complications are due to the consumption of unhealthy foods during the pregnant period, which is somehow guided by the socio-cultural norms. Overall, the safe motherhood practices in this community are found moderately adequate but it needs improvement to provide better health care systems to the women in rural settlements. In this regard, the antenatal, natal, and postnatal services must be delivered free of cost. It is recommended to enhance the consumption of nutrient food habits during the pregnant period for strengthening the immune system of the mothers. Further, the safe motherhood practices and the timely visit to the health post centers by pregnant women during antenatal, natal, and postnatal periods are necessary to reduce the maternal mortality rate. 


\section{References}

Adhikari, P.C. (2010). Safe motherhood practice of Dalit community of Nabal Parasi District [Unpublished MA Thesis, Tribhuvan University]. Kathmandu: Department of Health, Physical and Population Education, Kirtipur.

Ashford, L. (2001). New population policies advancing women's health and Right, population Bulletin, 56(2). P.12

Badal, B.P. (2019). Tourism: Visit Nepal 2020, Research Nepal Journal of development Studies, 2(2), PP. 12-30.

Bhandari, T. R. (2012). Maternal health issues of Nepal and ways forward. JHAS, 2(1), 64-69

Creswell, J. W. (2014). Research design: Qualitative, quantitative and mix methods approaches (4th ed.). Los Angeles: University of Nebraska-Lincoln: Sage Publication.

Gupta, C. B. \& Gupta, V. (2015). An introduction to statistical methods (23rd ed.). Delhi: Vikas Publishing House.

Krejcie, R. V. \& Morgan, D. W. (1970). Determining sample size for research activities. Educational and Psychological Measurement, (30), 607-610.

Luitel, C. (2004). Population of Nepal (1st ed.). Kathmandu: Nima Pustak Parkasan.

Ministry of Health and Population (2018). National annual review report. Kathmandu: Government of Nepal.

Moore, B. N. \& Bruder, K. (2007). Philosophy: The power of ideas (6th ed.). New York, NY: The McGraw-Hill Companies.

Organization for Economic Cooperation and Development (OECD). (2018). Population and migration report. Author.

Patel, B. (2000). WHO regional health forum, 4(1 \& 2), 77-80.

Portela, A. \& Santarelli, C. (2003). Empowerment of women, men, families and communities: True partners for improving maternal and newborn health. British Medical Bulletin. Doi:http://10.1093/bmb/ldg011

Panch Pokhari Thangpal Rural Municipality (PPTRM). (2019). Profile of Panch Pokhari Thangpal Rural Municipality, 2018, Sindhupalchwok. Author. 
Subedi, P. (2002). Teenage pregnancy and its effect on child and mother health in the Chepang community of Dhading District [Unpublished master's Thesis, Tribhuvan University]. Kathmandu: Department of Health Population and Environment, Kirtipur.

United Nations International Children Emergency Fund (UNICEF) (2001). Children and women of Nepal: A situational Analysis. Kathmandu: UNICEF.

United Nations (2017). Internal migration report, 2017. New York: Department of Economics and Social Affair, Population Division.

United Nations (UN) (2017). The world's women 2015 trends and statistics: Economic and statistical affairs. New York: Department of Economic and Social Affairs. Doi: http:// 10.18356/9789210573719 e-ISBN: 978-92-1-057371-9

World Bank (WB). (2019). World population prospect. Washington DC: Author.

Yin, R. K. (2014). Case study research: Design and method (4th ed.). Thousand Oaks, CA: Sage Publication. 